\title{
Alteraciones geomorfológicas recientes en los sistemas fluviales mediterráneos de la Península Ibérica. Síntomas y problemas de incisión en los cauces ${ }^{1}$
}

\author{
Carmelo Conesa García ${ }^{2}$ y Pedro Pérez Cutillas ${ }^{3}$
}

\begin{abstract}
RESUMEN
Con el presente artículo se pretende dar una visión general de los recientes ajustes morfológicos que han sufrido los sistemas fluviales mediterráneos en la Península Ibérica a causa de la acción del hombre. En primer lugar, se exponen las principales actuaciones que alteran la cuantía y el régimen de sus aportaciones de aguas y sedimentos. Tras analizar la actual situación de inestabilidad y ruptura del equilibrio natural de muchos de estos sistemas, incluyendo las Ilanuras aluviales, se estudian los cambios más importantes observados en la morfodinámica de los cauces. Con especial detalle, por sus repercusiones ambientales y socioeconómicas, ha sido abordado el análisis de la creciente tendencia a la incisión del cauce durante las últimas décadas, así como su relación con la gestión de los recursos hidrológicos y las distintas acciones llevadas a cabo en cuencas y cursos de agua.
\end{abstract}

Palabras clave: Alteración geomorfológica, sistemas fluviales, área mediterránea española.

\begin{abstract}
This work gives and overview of the recent morphological adjustments to Mediterranean fluvial systems in Spain caused by human action. First, we discuss the main actions affecting the amount and rate of water and sediment discharge. After analyzing the current conditions of instability and natural imbalance in most of these systems, we studies the important changes observed in the morphodynamics of channels and alluvial plains. We then analyze, in detail, the marked increase in bed incision, particularly over the last decades, which has both environmental and socioeconomic impacts, in relation to the management of the hydrological resources and the different actions undertaken in watersheds and waterways.
\end{abstract}

Key words: Geomorphic adjustments, fluvial systems, Spanish Mediterranean region.

1 El presente artículo ha sido realizado en el marco del proyecto DYCAM-SEG, "Dinámica y cambios morfológicos recientes del Bajo Segura (Vega Media)", con la financiación de la Fundación SENECA, Agencia de Ciencia y Tecnología de la Región de Murcia, España, Referencia 15224/PI/10. Artículo recibido el 24 de junio de 2013, aceptado el 15 enero de 2014 y corregido el 27 de enero de 2014.

2 Departamento de Geografía, Universidad de Murcia (España). E-mail: cconesa@um.es

3 Departamento de Geografía, Universidad de Murcia/ Consejo Superior de Investigaciones Científicas (España).E-mail: perezcutillas@cebas.csic.es 
La vertiente mediterránea española se compone de cuencas de drenaje muy variadas y de cursos de agua con regímenes hidrológicos bien diferentes (permanente, estacional y efímero), no exentos en ningún caso de importantes crecidas ocasionales asociadas a fuertes lluvias (Conacher \& Sala, 1998). El carácter torrencial de muchos de estos cursos, unido a la fuerte erosión que desencadenan en situaciones de aguas altas, han venido siendo durante mucho tiempo los agentes principales de una acelerada morfogénesis en equilibrio con tales condiciones. Sin embargo, la intensa ocupación de las Ilanuras aluviales y las múltiples acciones, no siempre acertadas, emprendidas recientemente en zonas de cabecera han terminado por modificar de manera radical dicha morfodinámica fluvial. Durante el último siglo se han llevado a cabo numerosas actuaciones con fines de regulación hidrológica (embalses), de restauración hidrológico-forestal (repoblaciones, diques de retención), de protección contra inundaciones (motas, malecones, encauzamientos), de explotación de recursos (canteras de áridos), etcétera, que han alterado profundamente aguas abajo el balance de agua y sedimento y, con ello, la morfología de los cauces. En definitiva, toda una serie de perturbaciones introducidas por el hombre en un sistema ambiental de frágil equilibrio como es el fluvial mediterráneo (Carmona y Olmos, 1994).

Ramblas y barrancos constituyen, dentro de este ámbito, el principal sistema de transporte de sedimentos (a) desde las montañas, colinas y laderas hacia los piedemonte, tierras bajas y embalses; y (b) desde las áreas de erosión al mar, produciendo destacados fenómenos de sedimentación y acreción costera. Alcanzan su mayor dinamismo en áreas semiáridas del Sureste Ibérico, donde pueden llegar a evacuar grandes caudales durante breves intervalos de tiempo (avenidas relámpago o flash floods). Debido al funcionamiento de este tipo de corrientes, repentino y discreto en el tiempo, los lechos de las ramblas registran fenómenos de erosión y de transporte muy complejos (López Bermúdez et al., 1998). La carga de fondo y la rugosidad del lecho, por ejemplo, presentan fuertes variaciones espaciales y temporales, que acusan sensiblemente los efectos de determinadas actuaciones (traviesas, espigones, diques).
El intenso uso de estos sistemas de drenaje efímero a lo largo de la historia (desviaciones de sus aguas para el riego por "boquera", canalizaciones, construcción de pozos en sus lechos, parcelas de cultivo, vías de comunicación, extracción de áridos, etcétera) ha supuesto una importante modificación de su dinámica hidrológica y geomorfológica, con indudable repercusión en los cursos principales a los que afluyen.

La magnitud de tales ajustes es todavía más incierta bajo un escenario de cambio climático global y de abandono progresivo del medio rural (Burlando et al., 1997). Los sistemas hidrológicos en medios frágiles como la montaña mediterránea son particularmente sensibles a dichos cambios (Verdú, 2003). La reciente tragedia de Biescas (García Ruiz et al., 1996), por ejemplo, pone de manifiesto la necesidad de un mejor conocimiento de la dinámica fluvial como base para una gestión adecuada de este tipo de espacios. Cualquier actuación que se planifique en torno a ellos ha de tener en cuenta sus mecanismos de autorregulación en condiciones naturales. De hecho, solo en aquellos casos en que han sido respetados sus diferentes grados de libertad geomorfológica (Martín Vide, 2006; Ollero y Romeo, 2007), los ríos, ramblas y barrancos han podido desarrollar una dinámica natural activa, en equilibrio con los cambios ambientales que los afectan. Por el contrario, abundan los casos donde la acción del hombre está provocando una gran alteración geomorfológica en este tipo de sistemas, cuyo verdadero alcance todavía hoy se desconoce.

\section{Caracterización de los cursos fluviales de la vertiente mediterránea peninsular}

Los cursos fluviales que drenan la vertiente mediterránea de la Península Ibérica son muy desiguales en extensión y comportamiento. El más importante, por su mayor longitud, caudal y regularidad, es el Ebro, que recibe los aportes de sus afluentes pirenaicos (Aragón, Gállego, Cinca y Segre) e ibéricos (Jalón, Guadalope) (Figura No 1). El resto de cursos (Ter, Llobregat, Turia, Júcar, Segura, Almanzora, Andarax, Guadalhorce) ofrecen un menor desarrollo longitudinal y pendientes generalmente más acusadas, 
dada la relativa proximidad a la costa de los relieves que definen sus líneas divisorias de aguas (Sistema Ibérico y Sistema Bético). Estos cursos fluviales presentan condiciones de gran penuria hidrológica e irregularidad, con frecuentes crecidas y acusados estiajes (Conacher \& Sala, 1998). Los ríos catalanes, Fluviá, Ter y Llobregat, con un régimen de alimentación mixto, son cortos y algo más caudalosos. En cambio, los levantinos, el Mi- jares, Palancia, Turia, Júcar y Segura, tienen cuencas de tamaño pequeño o mediano, un régimen de alimentación pluvial o pluvionival y una gran irregularidad interanual y estacional. Finalmente, los ríos meridionales de régimen pluvial mediterráneo subtropical, Almanzora, Guadalfeo y Guadalhorce, son muy cortos, rápidos e irregulares, de difícil aprovechamiento $y$, al igual que los levantinos, proclives a grandes crecidas.

Figura $\mathrm{N}^{\circ} 1$

Localización de las cuencas vertientes mediterráneas en el contexto hidrográfico de la Península Ibérica

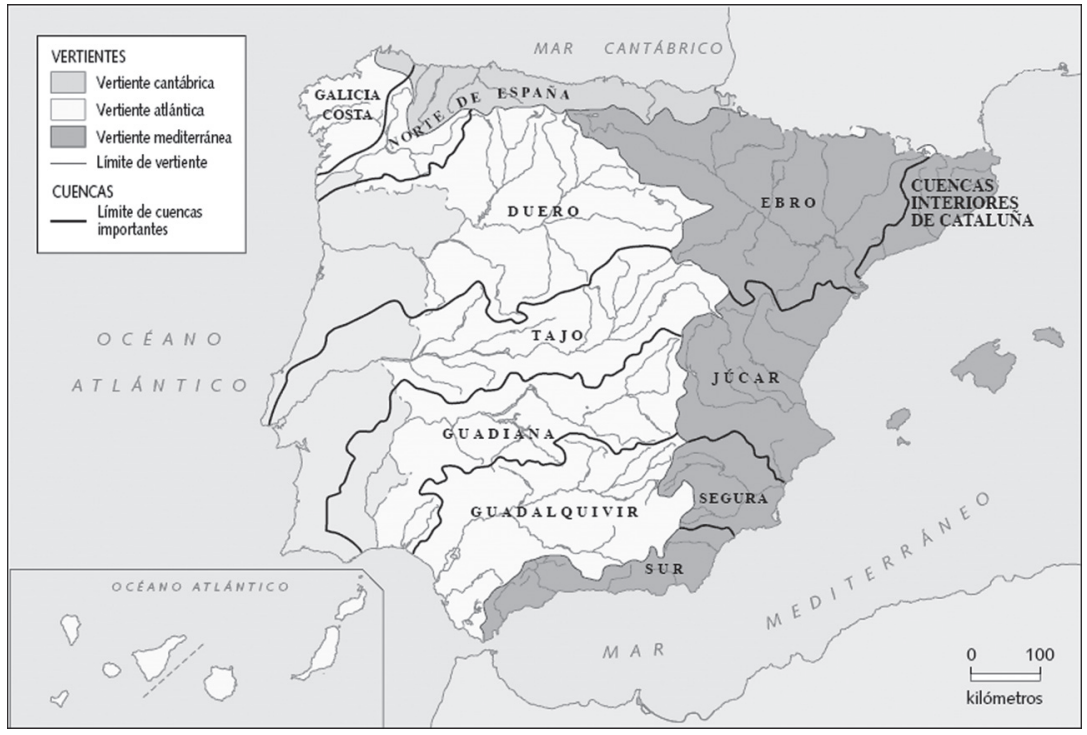

Fuente: wiki-chemageo.wikispaces.com

En toda el área mediterránea, y en particular en el Sureste español, existen numerosos cauces efímeros, denominados ramblas (o rieras en Cataluña), cauces anchos, de sustrato pedregoso, secos y que solo transportan agua de forma muy rápida tras fuertes Iluvias (Mateu, 1989: Pulido Bosch, 1993; Conesa García, 2005). Sus lechos, especialmente activos durante las avenidas, son bastante sensibles a todo tipo de intervención antrópica y se muestran inestables largos intervalos de tiempo.

\section{Principales actuaciones en cuencas y cursos fluviales}

La importancia que actualmente adquiere la erosión en muchas zonas de cabecera de las cuencas fluviales mediterráneas en España es, sin duda, producto de los numerosos errores cometidos durante el pasado en la gestión y uso de sus montes. Desde muy antiguo estas áreas fueron sometidas a una continua utilización del bosque (Fernández-Galiano, 1990) y a prácticas muy arraigadas que contribuyeron de forma decisiva a la degradación de la cubierta vegetal mediterránea, la más común el pastoreo de ovinos y caprinos en régimen de trashumancia. La destrucción masiva de la cobertura vegetal de grandes superficies en el largo período de la Reconquista (siglos VIII al XV), el pastoreo excesivo promovido por la Mesta en tiempos de los Reyes Católicos, la tala indiscriminada para la obtención de madera con usos industriales en la Edad Moderna (construcción de barcos 
para la Armada española) y tras la revolución industrial (construcción de ferrocarriles), o como combustible hasta después de la Guerra Civil española han sido factores decisivos en la impronta paisajística de muchas laderas hoy carentes de vegetación y expuestas a una fuerte denudación.

Ante este panorama desolador, surge en España a principios del siglo XX, al igual que en el resto de Europa, una cierta preocupación por la restauración forestal de las áreas de montaña. No obstante, desde la creación de las Divisiones Hidrológico-Forestales en 1901 las actuaciones en materia de repoblación forestal y obras de corrección de cauces han seguido una evolución desigual. Según se aprecia en la Figura $N^{\circ} 2$, la superficie repoblada experimenta un crecimiento progresivo desde 1940 hasta 1946 y otro de ritmo más acusado a partir de 1952, alcanzando un máximo de repoblación en 1957 (136.000 ha). En la década de los sesenta se produce una estabilización de los créditos, manteniendo una tasa media de 100.000 ha/año hasta 1971.

Figura $\mathrm{N}^{\circ} 2$

Repoblaciones y obras de corrección hidrológica (1940-1999).

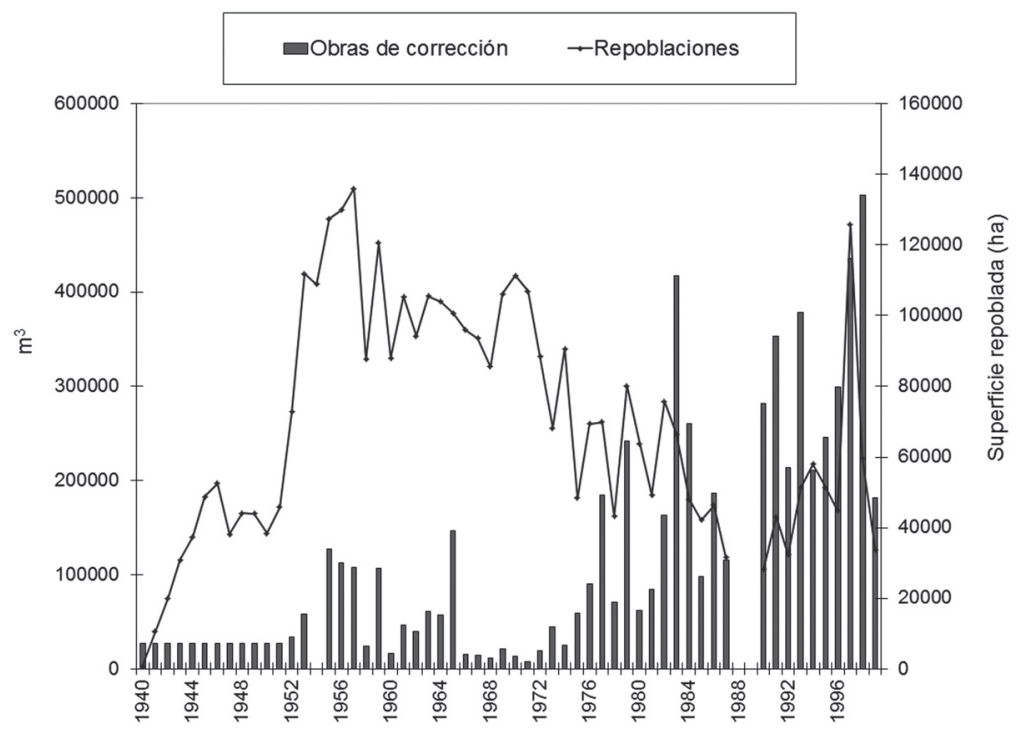

Fuente: Elaboración propia a partir de datos del GT8 VII CNMA (2004).

Con la creación del Instituto para la Conservación de la Naturaleza (ICONA), la superficie media repoblada se sitúa en torno a 68.000 ha anuales. Poco después del traspaso de las competencias de gestión forestal a las Comunidades Autónomas (mediados de los ochenta) se redujeron de nuevo los trabajos de repoblación. Sin embargo, en la década de los noventa, se ha producido una ligera recuperación, que puede ser consecuencia, entre otras causas, de la consolidación de dicha gestión, de la elaboración de las estrategias y planificaciones autonómicas y del apoyo financiero de los Fondos Estructurales y de Cohesión de la UE. El volumen de obras de corrección hidrológica en España registra un considerable incremento a partir de 1977 $y$, salvo la etapa final de los años ochenta, se mantiene por encima de los $225.000 \mathrm{~m}^{3} / \mathrm{año}$, superando los $400.000 \mathrm{~m}^{3}$ en 1983 y 1998. Buena parte de estos volúmenes, entre el 27 y el 39\% según los años, corresponden a cuencas de la vertiente mediterránea, ocupando un lugar destacado la construcción de estructuras transversales de corrección de cauces (espigones, diques, albarradas y umbrales de fondo). 
El papel de los embalses en la retención de sedimentos

La construcción de embalses representa un grave problema al modificar el régimen hidrológico de los cursos de agua e interrumpir la transferencia de sedimentos aguas abajo. Frecuentemente, los embalses almacenan más del 90 por ciento de la carga de sedimentos suministrada por sus cuencas de drenaje, experimentando un relleno progresivo que continuamente modifica su grado de eficacia. Reducciones medias anuales de la capacidad de almacenamiento entre 0,3 y 3,9\% se han observado en las cuencas vertientes a los embalses del río Segura (López Bermúdez, 1986; Romero Díaz et al., 1992) y de 0,4 \% en la cuenca del embalse de Riba-Roja d'Ebre (Freixas y Jiménez, 2012). Desde la puesta en explotación hasta las fechas de realización de las batimetrías (1980-1990), han perdido más del $30 \%$ de su capacidad los embalses de Valdeinfierno, Talave, Alfonso XIII y Puentes, mientras que los embalses de Moneva, Barasona, Talarn-Trempt, Pena, Oliana, Guadalest y La Cierva la han visto reducida entre un $15 \%$ y un $30 \%$. Las degradaciones específicas de mayor cuantía corresponden a las cuencas de los embalses de Guadalest (Júcar), Pena (Ebro) y Cenajo (Segura) (De Antonio et al., 1995) (Cuadro No 1). Valores de degradación aún más altos fueron obtenidos por López Bermúdez y Gutiérrez Escudero (1982), a partir de batimetrías anteriores (1976 y 1977), en los embalses de la cuenca del Segura (p.e. La Cierva: 670 ton $/ \mathrm{km}^{2}$ año; Valdeinfierno: 1100 ton/ $/ \mathrm{km}^{2}$ año; Alfonso XIII: 1020 ton $/ \mathrm{km}^{2}$ año). Resulta singularmente Ilamativo el caso de la presa de Valdeinfierno que, tras su rápido proceso de colmatación, tuvo que ser recrecida en varias ocasiones desde su construcción en 1806.

\section{Cuadro $\mathrm{N}^{\circ} 1$}

Datos de retención de sedimentos obtenidos por batimetrías para diferentes embalses de las cuencas del Ebro, Júcar y Segura, con estimación de tasas de erosión específica

\begin{tabular}{|l|l|l|r|r|r|r|r|}
\hline Embalse & Cuenca & \multicolumn{1}{|c|}{ Río } & $\begin{array}{c}\text { Fecha } \\
\text { consultada }\end{array}$ & VR (\%) & $\begin{array}{c}\text { EES' } \\
\left(\mathrm{t} / \mathrm{km}^{2} \text { año }\right)\end{array}$ & Cr (\%) & \multicolumn{1}{|c|}{$\begin{array}{c}\text { EES } \\
\left(\mathrm{t} / \mathrm{km}^{2} \text { año }\right)\end{array}$} \\
\hline Moneva & Ebro & Aguas Vivas & 1929 & 20,00 & 92,8 & 80,08 & 111,3 \\
Yesa & Ebro & Aragón & 1960 & 4,39 & 404,3 & 97,92 & 412,7 \\
Sotonera & Ebro & Astón & 1961 & 3,93 & 138,1 & 94,24 & 146,1 \\
Barasona & Ebro & Esera & 1932 & 15,96 & 152,1 & 90,15 & 167,1 \\
Talarn-Trempt & Ebro & N. Pallaresa & 1916 & 26,97 & 570,8 & 96,51 & 590,7 \\
Pena & Ebro & Pena & 1930 & 16,45 & $1.218,5$ & 98,49 & $1.236,8$ \\
Oliana & Ebro & Segre & 1969 & 15,05 & 246,1 & 87,92 & 275,8 \\
Guadalest & Júcar & Beniarda & 1967 & 18,80 & $2.620,8$ & 98,07 & $2.671,5$ \\
Forata & Júcar & Magro & 1969 & 4,64 & 108,1 & 88,36 & 120,7 \\
Valdeinfierno & Segura & Caramel & 1897 & 49,40 & 473,9 & 92,71 & 508,4 \\
La Cierva & Segura & Mula & 1929 & 25,71 & 230,2 & 89,14 & 255,1 \\
Camarillas & Segura & Mundo & 1960 & 10,40 & 112,8 & 83.24 & 131,7 \\
Talave & Segura & Mundo & 1918 & 39,45 & 546,4 & 92,45 & 587,7 \\
Alfonso XIII & Segura & Quípar & 1916 & 43,30 & 308,7 & 89,02 & 342,6 \\
Puentes & Segura & Luchena & 1884 & 59,27 & 177,1 & 81,22 & 210,4 \\
Cenajo & Segura & Segura & 1960 & 7,00 & $1.065,3$ & 98,57 & $1.080,6$ \\
\hline
\end{tabular}

Fuente: De Antonio et al. (1995). 
VR $(\%)=(\mathrm{Vr} / \mathrm{Vi}) \cdot 100 ; \mathrm{Vr}=$ Volumen de sólidos retenidos desde la puesta en carga; $\mathrm{Vi}=$ Capacidad inicial del embalse; EES' = Erosión específica del suelo en la cuenca vertiente ( $\mathrm{t} / \mathrm{km}^{-2}$ año), sin considerar los sedimentos que escapan del embalse; $\mathrm{Cr}=$ Coeficiente de retención de Brown en $\%$. $\mathrm{Cr}=100 \cdot[1-(1 /(1+\mathrm{k} \cdot \mathrm{Vm} / \mathrm{S}))] ; \mathrm{K}=$ 0,21 (tipo II); $\mathrm{Vm}=$ Capacidad media del embalse en millares de $\mathrm{m}^{3}=(\mathrm{Va}+\mathrm{Vi}) / 2$; $\mathrm{Va}=$ Capacidad actual del embalse; $\mathrm{S}=$ Superficie de la cuenca en $\mathrm{km}^{2}$; EES = Erosión específica del suelo en la cuenca vertiente ( $\mathrm{t} / \mathrm{km}^{-2}$ año). Período de mediciones batimétricas: 1980-1990.

En la actualidad la colmatación de embalses es un problema ambiental de primer orden, en particular en la vertiente mediterránea española, donde la erosión potencial (y real) afecta con intensidad a un buen número de ríos y ríos-rambla regulados. Ciertamente las consecuencias ambientales de la colmatación de embalses van más allá de la regresión de deltas o las pérdidas de volumen embalsable, ya que afectan de forma significativa la morfodinámica de los sistemas fluviales aguas abajo de las presas.

\section{La construcción de densas redes de infraestructuras menores}

Dentro de este ámbito mediterráneo abundan también otras infraestructuras de menor entidad, pequeñas presas y azudes para el regadío y la derivación de aguas, sin capacidad reguladora importante, pero que pueden alterar sensiblemente el régimen de caudales circulantes. En Cataluña, se han identificado más de 900 azudes y pequeñas presas de derivación de caudales sobre una red fluvial de 4.000 km (García de Jalón et al., 2007). En numerosas ramblas del Sureste español han tenido especial importancia los sistemas de derivación de aguas de avenida, algunos de ellos implantados desde época romana. Generalmente consisten en sencillos azudes de derivación, construidos a veces con el propio material del lecho, cuya finalidad es conducir el agua hacia bancales contiguos a la rambla (Pulido Bosch, 1993). Estas aguas turbias constituyen la única fuente de mantenimiento de la vegetación en muchas zonas áridas y semiáridas (Ayuso et al., 1982). En el Alto Guadalentín (cuenca del río Segura), por ejemplo, existe una antigua infraestructura de canales, portillos y boqueras que distribuyen sus aguas de avenida a las parcelas de cultivo vecinas. Las ramblas, consideradas como uno de los elementos geomorfológicos más activos y peculiares del Sureste peninsular (Gómez et al., 2005), han sido objeto de un intenso uso a lo largo del tiempo. La precariedad constante de sus aportaciones hídricas salpicada de abultados flujos esporádicos han hecho desarrollar sistemas hidráulicos de extracción y conducción que permiten maximizar su aprovechamiento, desde molinos harineros instalados en las riberas de las ramblas con actividad fluvial más reciente (Segura, 1990), hasta los sistemas de captación y acumulación de agua en ramblas completamente secas que han permitido incluso el desarrollo de una actividad agrícola de regadío (Muñoz y Navarro, 2000). Destacan en este sentido la organización de terrazas de cultivo dispuestas de forma escalonada en torno al cauce con el fin de aprovechar al máximo sus aguas de escorrentía, reteniendo parte de ellas y frenando su acción erosiva (Morales Gil, 1968).

\section{Equilibrio o ruptura en la morfodinámica fluvial mediterránea}

Los sistemas fluviales naturales rara vez alcanzan un perfecto estado de equilibrio. No solo varían las características hidrodinámicas de las corrientes, sino también sus formas y procesos. El resultado de este continuo cambio es una variación concomitante con la morfología global del sistema (cauce y llanura de inundación), que al cabo de los años termina dando paso a una estabilidad relativa (Conesa García, 1999). En cuencas y cursos de agua fuertemente alterados por la acción del hombre, como la mayoría de los que vierten al Mediterráneo Occidental, se observa una aceleración en estos cambios morfológicos, acordes con los rápidos ajustes de los caudales sólido y líquido, de la pendiente del cauce y del tamaño de las partículas transportadas. Las alteraciones geomorfológicas de muchos ríos y ramblas mediterráneos españoles son bastante graves (Figura $N^{\circ} 3$ ). Hay incluso modelos de cauces especialmente activos, como los cursos trenzados (braided), que están a punto de desaparecer (Ollero et al., 2008). El origen básico de estas alteraciones 
se encuentra en el propio desarrollo socioeconómico de las áreas, con actividades que consumen territorio (espacio fluvial), agua y sedimentos (áridos), y con exigencias sociales de protección (frente a inundaciones), estabilidad (frente a dinámica) e integración en medios urbanos (frente a naturalidad) (Ollero y Romeo, 2007). La situación de equilibrio dinámico que venían manteniendo los cursos del ámbito mediterráneo español con la alte- ración, a largo plazo, de las condiciones ambientales de sus cuencas, está perdiendo en muchos casos protagonismo frente a la aparición cada vez más frecuente de escenarios con ajustes morfológicos bruscos inducidos por el hombre. A menudo, los ajustes graduales y progresivos de los antiguos sistemas fluviales son reemplazados o interrumpidos por cambios más rápidos en repuesta a actuaciones invasivas de su espacio natural.

Figura $\mathrm{N}^{\circ} 3$

Grado de alteración de los cursos fluviales mediterráneos españoles. Grado de alteración potencial del régimen hidrológico obtenido a partir del cociente entre el volumen de embalse y la aportación natural circulante aguas arriba

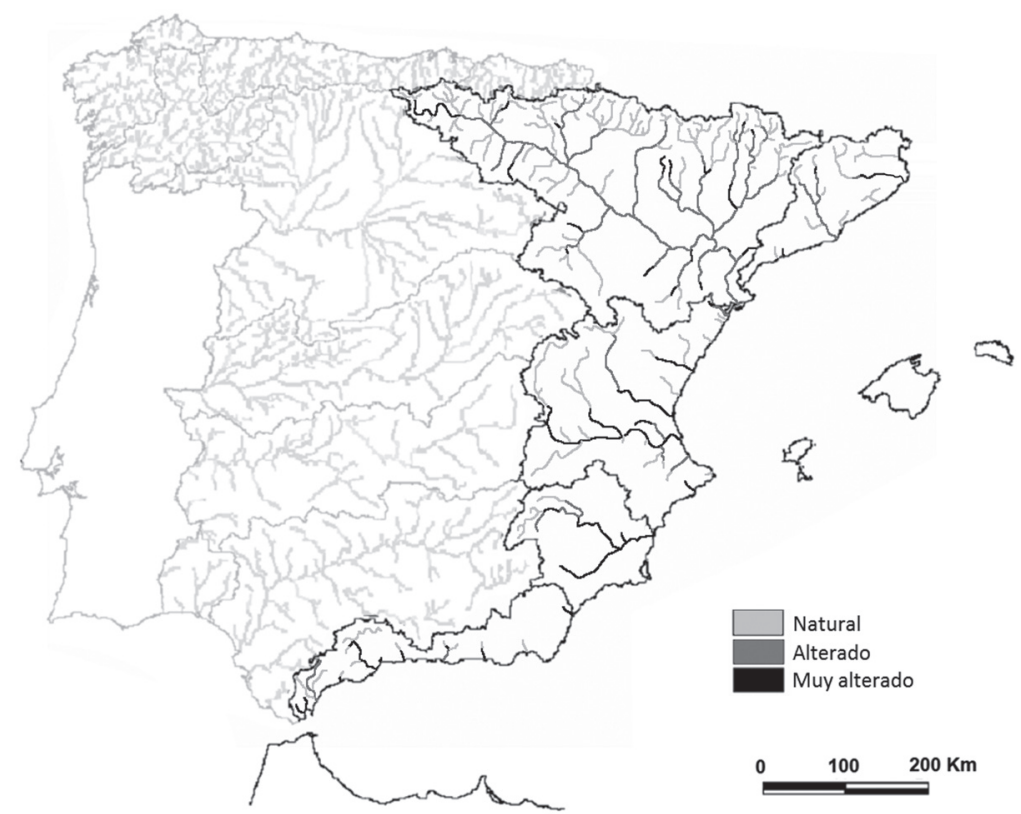

Fuente: García de Jalón et al., 2007.

En la actualidad se asiste a un profundo y complejo cambio de los umbrales de equilibrio, como consecuencia del solapamiento de ajustes a corto y medio plazo, forzados por una intensa acción del hombre. De un equilibrio de régimen discontinuo -equilibrio dinámico, metaestable- (Schumm, 1977) influido por umbrales que controlaban la dinámica general de la corriente, se está pasando a constantes situaciones de desequilibrio temporal, a veces superpuestas, que no terminan de alcanzar un nivel de estabilidad. Estas modificaciones inducidas por el hombre incluyen efectos directos causados por medidas de gestión, obras de acondicionamiento del río y regulación de sus caudales, y cambios indirectos asociados a alteraciones en los usos del suelo de la cuenca, cuya repercusión en la producción de sedimentos y escorrentía genera nuevas condiciones medioambientales a las que el sistema fluvial responde con relativa rapidez (Conesa García et al., 2007). 
La dinámica cambiante de las llanuras aluviales

En el ámbito mediterráneo español las Ilanuras aluviales muestran una dinámica reciente bastante parecida, sobre todo debido a su intensa ocupación por el hombre y la frecuente regulación hidrológica practicada aguas arriba. A pesar de ello, las particu- laridades ambientales de cada cuenca se hacen notar sensiblemente en el desarrollo de las llanuras de inundación aguas abajo. El Cuadro № 2, confeccionado a partir de un amplio repertorio bibliográfico, expresa los factores de cambio del cauce y las respuestas de este más comúnmente observadas en las Ilanuras aluviales mediterráneas de la Península Ibérica.

\section{Cuadro $\mathrm{N}^{\circ} 2$}

Respuestas del cauce más comunes ante procesos naturales y antropogénicos que actúan como factores de ajuste morfológico en llanuras aluviales de la vertiente mediterránea española

\begin{tabular}{|c|c|c|c|c|c|c|}
\hline \multirow{2}{*}{\multicolumn{2}{|c|}{ Factores de cambio del cauce }} & \multicolumn{5}{|c|}{ Respuestas del cauce más comunes } \\
\hline & & \multirow{2}{*}{$\frac{\text { Wc }}{\text { Aumenta }}$} & \multirow{2}{*}{\begin{tabular}{|c|} 
Lc \\
Decrece debido \\
a las avulsiones \\
\end{tabular}} & $\lambda$ & $\mathrm{T}_{\mathrm{i}}$ & $\mathrm{T}_{\mathrm{av}}$ \\
\hline Naturales & $\begin{array}{l}\begin{array}{l}\text { Grandes inunda- } \\
\text { ciones }\end{array} \\
\end{array}$ & & & Aumenta & Variable* & Aumenta \\
\hline & $\begin{array}{l}\text { Inundaciones } \\
\text { moderadas (lecho } \\
\text { activo inundación) }\end{array}$ & Aumenta & $\begin{array}{c}\text { Aumenta con la } \\
\text { migración }\end{array}$ & Aumenta & Variable* & Aumenta \\
\hline \multirow{5}{*}{ Antropogénicos } & \begin{tabular}{|l|} 
Pérdida de \\
vegetación ribereña
\end{tabular} & Aumenta & Aumenta & Sin datos & Decrece & Variable \\
\hline & $\begin{array}{l}\text { Retirada de } \\
\text { obstáculos }\end{array}$ & Decrece & $\begin{array}{l}\text { Aumenta o } \\
\text { decrece }\end{array}$ & Variable & Aumenta & Decrece \\
\hline & $\begin{array}{l}\text { Revestimiento del } \\
\text { cauce }\end{array}$ & Decrece & Se estabiliza & Se estabiliza & Aumenta & Decrece \\
\hline & $\begin{array}{l}\text { Construcción de } \\
\text { Presas aguas arriba }\end{array}$ & Decrece & Se estabiliza & $\begin{array}{c}\text { Decrece o } \\
\text { Se estabiliza }\end{array}$ & Aumenta & Decrece \\
\hline & $\begin{array}{l}\text { Modificaciones } \\
\text { del cauce (cortas } \\
\text { de meandros, } \\
\text { espigones, diques, } \\
\text { dragados, etc.) }\end{array}$ & Decrece & Se estabiliza & $\begin{array}{c}\text { Decrece o } \\
\text { se estabiliza }\end{array}$ & Aumenta & Decrece \\
\hline
\end{tabular}

Fuente: Elaboración propia a partir de referencias bibliográficas (Ménanteau y Vanney, 1985; Carmona y Olmos, 1994; Conesa García, 1995; Ollero, 1996, 2004; Uribelarrea et al., 2003; Jaso et al., 2007; Acín Naverac et al., 2011; CHJ, 2011; Conesa García et al., 2012).

$\mathrm{Wc}=$ anchura del cauce; $\mathrm{LC}=$ longitud del cauce; $\lambda=$ longitud de onda; $\mathrm{T}_{\mathrm{i}}=$ tasa de incisión del lecho; $\mathrm{T}_{\mathrm{av}}=$ tasa de avulsión. * Aumenta temporalmente por erosión transitoria.

Las alteraciones y ajustes morfológicos más notorios corresponden a los tramos medios y bajos de los ríos Ebro, Turia, Júcar y Segura. En dichos tramos, el cauce del Ebro ha registrado a lo largo de la historia continuos cambios de trazado, asociados a procesos de avulsión, cortas naturales y migraciones de meandros. Sin embargo, en la actualidad su movilidad se halla muy limitada debido a los ingentes volúmenes de sedimentos retenidos en los embalses y a la proliferación de defensas que sujetan las orillas. Las fotografías aéreas de 1927 son un documento excepcional que muestra un Ebro totalmente distinto al actual (Ollero, 1996, 2007). Apenas contaba con sotos, y mostraba una dinámica muy torrencial, con extensas superficies de gravas sin colonizar. En estos tramos, así como en 
la Plana de Castellón y en el Bajo Segura la Ilanura aluvial ha perdido buena parte de su funcionalidad. En particular el cauce del Bajo Segura presenta, desde hace siglos, un escaso margen de movilidad, siendo a finales del siglo XX cuando alcanza su máxima estabilización debido a numerosas cortas artificiales y a su total encauzamiento (Conesa García et al., 2012).

En el caso del Turia la extensa Ilanura aluvial desarrollada en torno al área que actualmente ocupa la ciudad de Valencia también denota la impronta del hombre en su etapa reciente. En particular, la parte adyacente a la margen izquierda del río ha sufrido frecuentes alteraciones morfológicas (formas de erosión cambiantes, direcciones de flujo contrarias, imbricación de depósitos con texturas diferentes, entre otros). La enorme carga de sedimentos aportada por el río a esta zona, y a buena parte de la llanura costera, durante las crecidas, refleja la importancia de la erosión en su cuenca vertiente, a raíz de la intensa deforestación que debió de acompañar la puesta en explotación de las tierras del interior (Carmona y Olmos, 1994).

Actualmente, las infraestructuras hidráulicas y viarias ejercen una importante influencia sobre el funcionamiento y ajustes morfológicos de las Ilanuras de inundación dentro del ámbito mediterráneo español. Destaca, por ejemplo, la gran cantidad de obstáculos existentes en la Plana inundable de Castellón, debido a la presencia de densas redes de acequias y de numerosas vías de comunicación, lo que provoca en la zona un comportamiento hidráulico de claro carácter bidimensional (Jaso et al., 2007). Efectos similares se observan en la Ilanura aluvial de otros muchos ríos mediterráneos españoles, entre ellos el Arga, Ega, Aragón, Ebro y Bajo Segura, siendo este último el espacio que cuenta con la red más densa de obras de acondicionamiento y derivación.

\section{Asistiendo a claros síntomas de una incisión creciente de los cauces}

Aguas abajo de los embalses se producen diversos efectos y cambios geomorfológicos, entre ellos una drástica reducción de la carga sedimentaria, unida a procesos de incisión del cauce, engrosamiento de los materiales del lecho y constricción lateral (López Alonso et al., 2004; Palau, 2006), la disminución de la actividad morfosedimentaria del sistema global (Johnson, 1992), la erosión costera y el retroceso de los deltas (García de Jalón et al., 2007). Pero, sin lugar a dudas, son la incisión y los ajustes que de ella derivan, las manifestaciones geomorfológicas recientes más sintomáticas y menos conocidas dentro del ámbito de estudio que nos ocupa. Existe una amplia bibliografía sobre la erosión local al pie de las presas y los cambios de trazado fluvial aguas abajo (Chien, 1985, Ligon et al., 1995; Simon \& Darby, 2001; Sear \& Newson, 2003), pero no abundan las referencias sobre el ritmo de incisión, las variaciones texturales del lecho o la erosión transitoria (Conesa García y García Lorenzo, 2007).

En la vertiente mediterránea peninsular la incisión del cauce se ha convertido en un problema preocupante no solo por su impacto sobre los ecosistemas sino también por el alto peligro que entraña para las obras de ingeniería expuestas (puentes, alcantariIlas, etcétera). En largos tramos medios del Cinca se observa una clara tendencia a la incisión, inducida desde mediados del siglo XX por la construcción de grandes embalses y cambios drásticos en los agrosistemas de montaña (Ollero et al., 2001). A medida que progresa la incisión, la dinámica general del cauce se hace más lenta, al tiempo que las barras de gravas pierden movilidad, disminuye el número de avulsiones y la corriente se concentra en un único brazo principal bien definido. La incisión del cauce se prolonga también en el tramo inferior del Ebro, debido al importante efecto adicional de los embalses de Mequinenza, Ribarroja y Flix (Vericat y Batalla, 2004). Desde su construcción en los años 70 la capacidad de la carga de fondo ha pasado de una media de 400.000 ton/año a menos de 100.000 ton/año durante la década de los 90. Según datos manejados por Batalla et al. (2008) en el periodo 2002-2004, estos embalses retienen hasta el $90 \%$ de la carga de materiales en suspensión $\left(1,4 \cdot 10^{6}\right.$ ton/ año), además de la totalidad de la carga de fondo. Ello origina una incisión sostenida del cauce aguas abajo que, en el caso de la presa de Flix, supone, según dichos autores, una exportación media neta anual de $0,18 \cdot 10^{6}$ 
ton de sedimentos gruesos del lecho y una incisión media de 30 mm/año.

Debido a la intensa regulación ejercida en cabecera por los embalses de Lanuza y Búbal, entre otros, el curso medio del Gállego (aguas abajo de Biescas) ha experimentado un profundo cambio en su modelo de cauce, pasando de un tipo trenzado a un tipo ligeramente sinuoso con canal único (Figura $\mathrm{N}^{\circ} 4$ ) (Ollero et al., 2004), con escasa renovación de material grueso y fitoestabilización de barras antiguas.

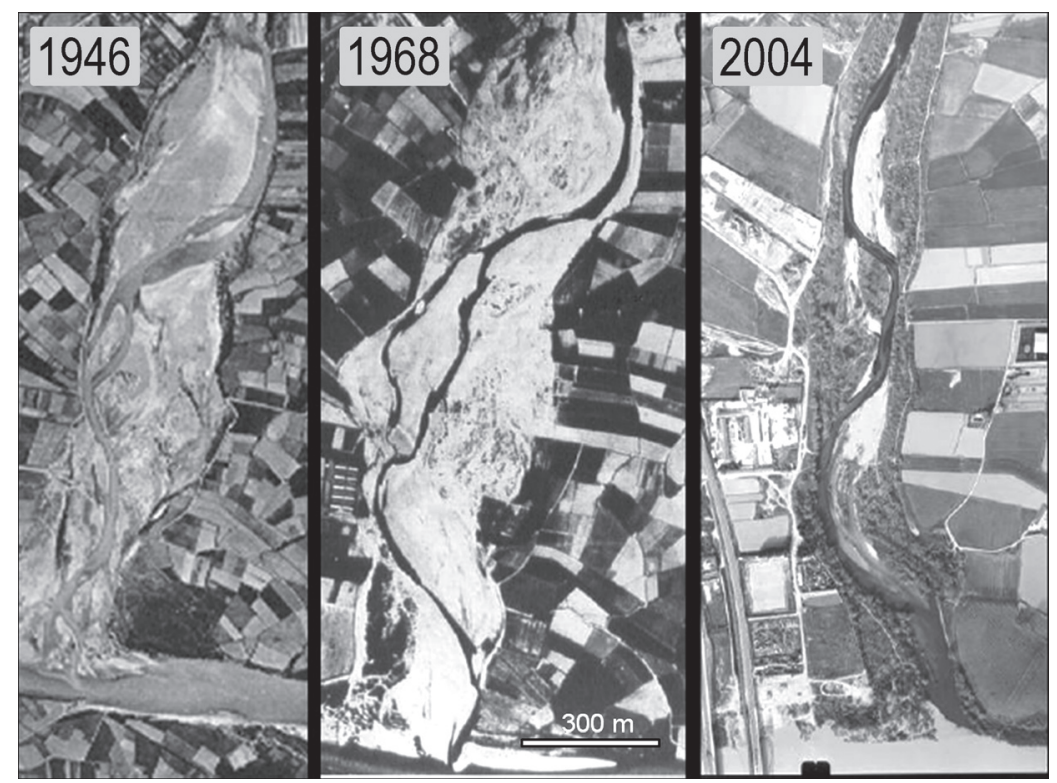

Fuente: Ayuntamiento de Zaragoza.

En el Sureste español la acción reguladora de los embalses reflejan una situación todavía más crítica por cuanto se reduce muy considerablemente los caudales punta de ríos y ríos-ramblas. La ocurrencia discreta de crecidas y avenidas que venían controlando la morfodinámica de estos sistemas fluviales queda en muchos casos totalmente interrumpida, de manera que los grandes ajustes globales tienden a ser reemplazados por procesos geomorfológicos de orden menor que afectan principalmente al cauce y a la línea de costa. Por ejemplo, la construcción del embalse de Amadorio en 1957 ha supuesto en el río del mismo nombre una notable disminución del volumen y calibre de los sedimentos aportados $y$, por consiguiente, una dinámica regresiva del tramo costero de Vilajoiosa (Torres, 2004). Sin embargo, la ro- tura de una gran presa, como la del embalse de Tous (Valencia) en octubre de 1982, puede originar una auténtica avalancha de agua y de sedimentos $y$, con ella, provocar cambios rotundos en todo el sistema aguas abajo.

Por su parte, la cuenca del río Segura, una de las más reguladas de Europa, ha asistido en las últimas décadas a una importante estabilización del cauce (Figura $N^{\circ}$ 5). Desde principios del siglo XX hasta la actualidad el tramo medio y bajo del Segura ha sufrido un acusado estrechamiento de su sección y procesos de incisión y acreción variables dentro del cauce principal. En general, la fuerte alteración de los flujos de agua y de sedimento hace que muchos de los tramos fluviales afectados tarden en recuperar su pendiente y perfil de equilibrio. Como con- 
secuencia de la incisión del cauce tiene lugar un rejuvenecimiento de los afluentes, que se empiezan a erosionar en dirección hacia su cabecera. Al erosionarse el cauce, el nivel base del agua que circula por el cauce principal disminuye, y los afluentes se ajustan a esta nueva situación erosionándose para así ajustar su pendiente a este nuevo nivel base. Un claro ejemplo lo constituye la erosión regresiva de la Rambla de Algeciras impuesta por un rebajamiento del nivel de base del río Guadalentín en su punto de afluencia. Cabe señalar que este río cuenta en cabecera con los embalses más antiguos de la cuenca del Segura (Valdeinfierno y Puentes).

La tendencia hacia modelos de cauce único más estables en planta suele estar acompañada, aguas abajo de las grandes pre- sas, por una densa colonización vegetal. De hecho, la menor movilidad del sedimento por el flujo circulante favorece el rápido establecimiento de la vegetación sobre barras, isletas y márgenes, dando estabilidad al cauce y contribuyendo a su estrechamiento. Desde la construcción, por ejemplo, de las presas de Mequinenza, Ribarroja y Flix la vegetación riparia fue invadiendo el cauce del río Ebro en un largo tramo aguas abajo (Sanz Montero et al., 2001), al tiempo que la anchura del lecho activo se reducía un 20\% (Vericat y Batalla, 2004).

En la Figura $N^{\circ} 6$, extraída de Sabaté et al. (2011), se pueden apreciar, a partir de la fotointerpretación de imágenes aéreas, los cambios del cauce del río Ebro relativos a grado de estabilización de barras y márgenes

Figura $\mathrm{N}^{\circ} 5$

Fases de evolución del Bajo Segura, desde 1928 a 2009, aguas arriba de la ciudad de Murcia. Obsérvese el cambio de un cauce más ancho y dinámico a otro confinado poco sinuoso
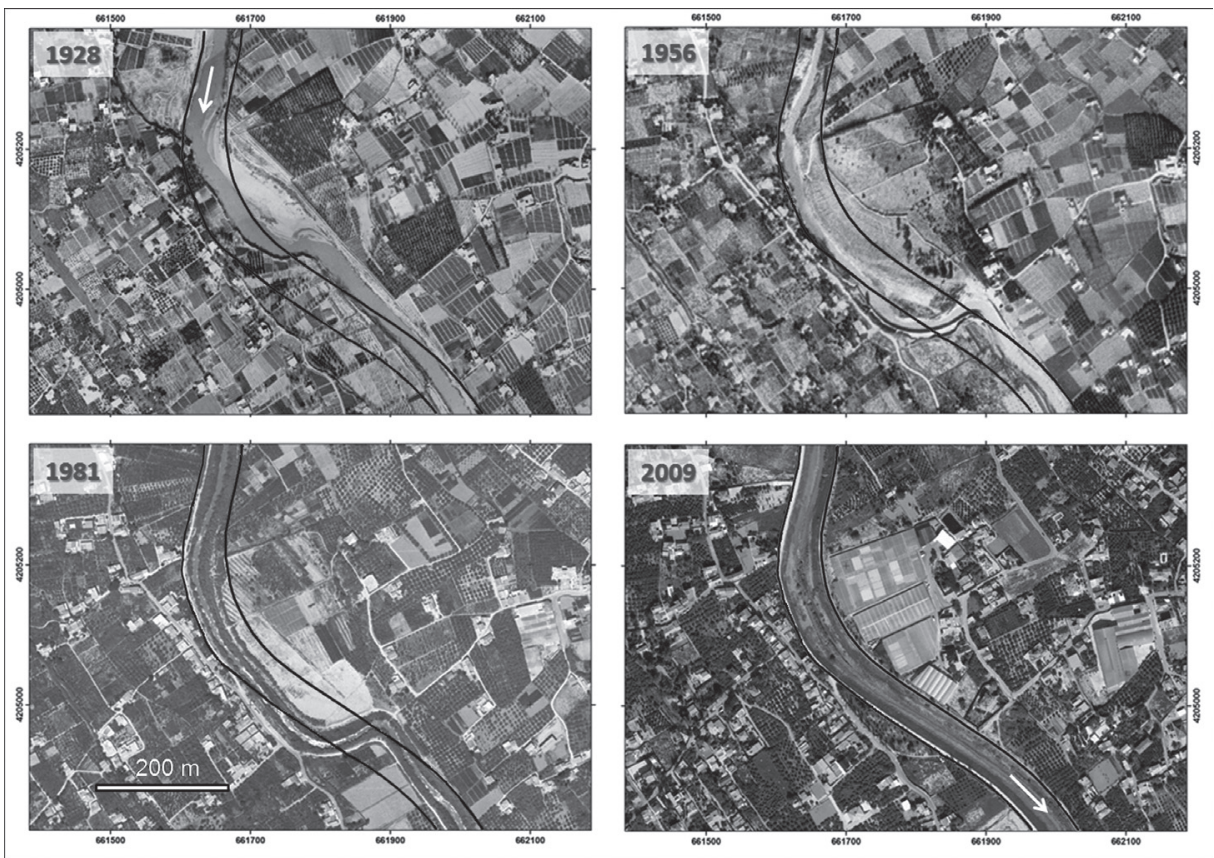

Fuente: Fotografías aéreas de los vuelos Ruiz de Alda (1928), USAF56 (1956) y Comunidad Autónoma de la Región de Murcia (1981), e imagen PNOA (2009).

naturales, aguas abajo del embalse de Flix. El crecimiento de la vegetación, primero arbustiva y después arbórea, no es más que la res- puesta natural a la falta de crecidas que ahora han menguado tanto en magnitud, como en frecuencia y duración. Así, en el tramo que 
discurre desde Flix hasta Vinallop, la reducción de la superficie de barras libres de vegetación ha sido superior al 90\% desde finales de los años cincuenta del siglo pasado, y en el caso de márgenes o diques naturales libres de vegetación su superficie se ha reducido en casi un $80 \%$ en el mismo periodo. A dicha reducción hay que sumar la reducción en un $40 \%$ de la superficie total de barras actuales respecto a finales de los años cincuenta, o de más del $20 \%$ en el caso de diques naturales (Freixas Borrel y Jiménez Mur, 2012). Otro ejemplo similar, aunque en menor escala, lo ofrece el río Algar, cuyo cauce aguas abajo de la presa de Mandem aparece invadido por densos cañaverales de Arundo donax (C.H.J., 2011). Este proceso se hace extensivo incluso a cauces efímeros dotados con grandes presas. Tal es el caso de la Rambla de Algeciras, aguas abajo de la presa de igual nombre, donde el cauce se halla totalmente ocupado por arbustos y matorrales altos (Atriplex halimus, Arthrocnemum sp. y Tamarix sp.).

Figura $\mathrm{N}^{\circ} 6$

Distribución de barras y diques naturales, y evolución de su grado de cobertura vegetal en el tramo del río Ebro aguas abajo del embalse de Flix.
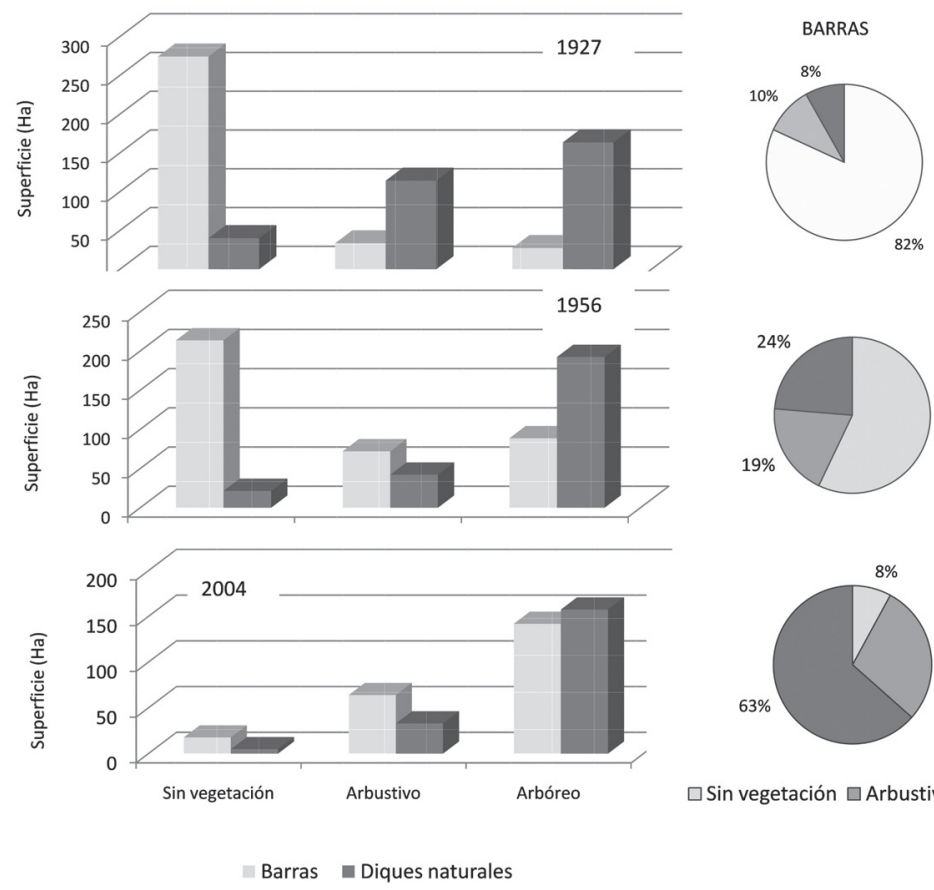

DIQUES NATURALES
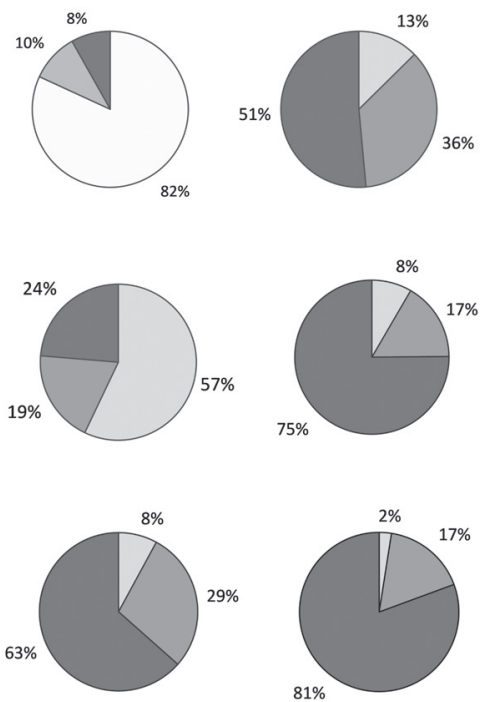

$\square$ Sin vegetación $\square$ Arbustivo $\square$ Arbóreo

Fuente: Elaboración propia a partir de datos de Sabaté et al. (2011).

Procesos de incisión ligados a acciones de lucha contra la erosión en cursos torrenciales

La construcción de diques de retención de sedimentos en cuencas torrenciales ha supuesto una importante reducción de los aportes sedimentarios aguas abajo. Un estudio llevado a cabo en varias áreas abarranca- das de la cuenca del Segura (Conesa García y García Lorenzo, 2007) atribuye a estas estructuras importantes ajustes morfológicos del cauce, entre ellos los siguientes relativos a la erosión del lecho: a) incisión del cauce aguas abajo y retrorrelleno aguas arriba, que implican en ambos tramos una modificación de la geometría de la sección transversal y de la ratio anchura/profundidad; b) formación 
de pozas y rápidos aguas abajo; c) variación de los niveles bankfull; d) conversión de antiguos lechos activos de inundación en terrazas aluviales aguas abajo e inundación ocasional de antiguas terrazas aguas arriba; e) desmantelamiento de la capa aluvial por causa de la erosión progresiva aguas abajo, dejando al descubierto el sustrato rocoso; f) reajuste de la pendiente de equilibrio, con una reducción sustancial de esta en los tramos entre diques; g) Erosión local y general transitoria menos importante que el volumen de sedimentos retenidos, dada la presencia de un sustrato rocoso poco profundo. El efecto más importante es, sin duda, la profunda alteración de los flujos de sedimentos provocada por dichos diques. El balance entre el volumen de material retenido aguas arriba y el volumen erosionado aguas abajo es muy diferente según las características ambientales de las áreas de drenaje. Ante condiciones topográficas y climáticas similares, la naturaleza litológica de las áreas fuente de sedimentos juega un papel decisivo en dicho balance. De hecho, dentro del Sureste peninsular se observan valores elevados de retención media efectiva (RME) en cuencas con predominio de materiales calizos (p.e. cuenca del Quípar, RME $=80 \%$ ) y valores bajos en cuencas de terrenos margosos (p.e. cuenca del Cárcavo, RME $=35,6 \%$ ). Las áreas metamórficas, constituidas principalmente por filitas, esquistos y pizarras, presentan valores también altos (p.e. cuenca de Torrecilla, RME $=68,1 \%$ )
(Conesa García \& García Lorenzo, 2010). Los diques instalados en terrenos de margas se rellenan a un mayor ritmo mostrando aguas abajo una profunda incisión del lecho que se traduce en altas tasas de remoción de material $\left(16,29 \cdot 10^{3}\right.$ ton/dique en la rambla del Cárcavo). Por el contrario, muchos de los diques construidos en terrenos metamórficos ejercen más una función hidrológica (recarga de acuíferos) que geomorfológica. Buen ejemplo de ello lo constituye el sistema de diques de la rambla de Torrecilla, donde la colmatación al cabo de 30 años solo se ha alcanzado en algunos de ellos, y la cuña de lecho erosionado aguas abajo apenas supone un desalojo de $1,05 \cdot 10^{3}$ ton/dique. Dependiendo del grado de resistencia relativa del lecho y los márgenes, la erosión local puede afectar solo al lecho o al conjunto del cauce. En el caso de la rambla del Cárcavo el afloramiento del sustrato calizo-margoso marca el fondo del nuevo cauce labrado aguas abajo de los diques. El acortamiento de los tramos en las zonas de lecho rocoso y la menor rugosidad relativa de este hace que la corriente de avenida registre aquí una mayor velocidad de la esperable, desplazando las formas de incisión aguas abajo. En otras ocasiones es la superficie "acorazada" inmediata al dique la que traslada aguas abajo la aparición de la cuña de erosión (Figura $N^{\circ} 7$ ).

La erosión generada al pie de un dique avanza progresivamente hasta que el lecho

Figura $\mathrm{N}^{0} 7$

Formas de incisión aguas abajo de diques de retención de sedimentos: (a) a partir de la rotura del lecho acorazado inmediato a una presa en la rambla del Cárcavo, y (b) sobre un abanico aluvial previo a la construcción del dique de cierre de la cuenca de Torrecilla
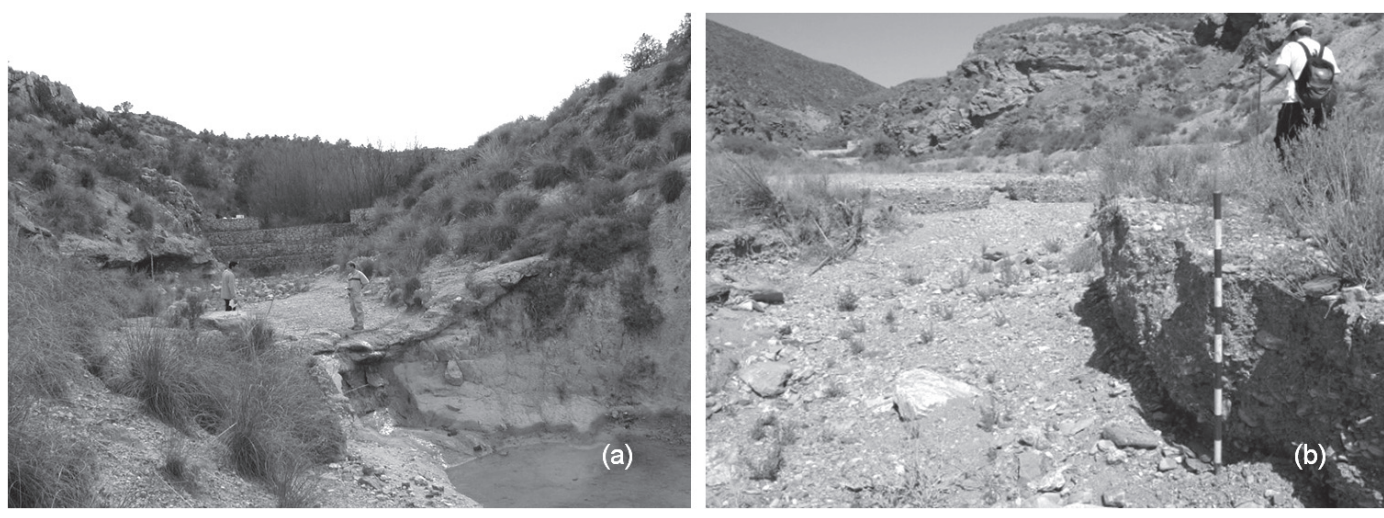

Fuente: Archivo personal de los autores. 
recupera su antiguo perfil de equilibrio, a expensas del tramo final de la cuña de sedimentos del dique precedente, que marca el nivel de base local de dicha erosión progresiva.

\section{Incisión versus acreción del lecho} asociada a acciones directas en tramos fluviales medios y bajos

Alteraciones geomorfológicas por acciones directas (canalizaciones, defensas, dragados, extracciones) sobre la forma del cauce, fondo y márgenes. Sus efectos son muy intensos localmente, con importantes repercusiones también aguas abajo que se manifiestan en el tiempo con bastante celeridad (Ollero et al., 2011). Los dragados y extracciones también repercuten aguas arriba por erosión remontante. Con frecuencia, se reduce la complejidad natural del trazado, transformando el cauce en un canal de desagüe. Ello implica incremento de la pendiente y de los procesos de incisión lineal en el fondo del lecho. El encauzamiento o rectificación de los ríos es quizá la intervención humana que más incertidumbre plantea en relación con los procesos de incisión y/o acreción del lecho en los tramos fluviales medios y bajos. Con este tipo de actuación se consigue generalmente un aumento considerable de la velocidad y de la tensión de corte del flujo, que favorecen los procesos de erosión en el lecho. Sin embargo, en tramos fluviales con tendencia a la acreción o colmatación, la menor probabilidad de desbordamiento asociada a la mayor capacidad hidráulica del encauzamiento puede llevar a acentuar dicha tendencia en el interior del propio cauce, haciendo recrecer la cota del lecho y obligando a elevar de nuevo las motas de protección (Martín Vide, 2006; Conesa García, 2012). Este es el caso del tramo bajo del Segura, que durante varios siglos ha visto recrecer sus motas quedando a menudo el lecho actual del cauce por encima de la llanura de inundación.

En muchos otros tramos se siguen proyectando y ejecutando obras de defensa y rectificación de cauces que los transforman en canales únicos, con el consiguiente aumento de la velocidad del flujo y de la erosión en zonas de lecho y márgenes cóncavos. Así, algunos sotos naturales de gran valor, madres y antiguos meandros han sido aislados del río mediante motas, como es el caso del Soto de la
Muga, donde la canalización del río Arga con escolleras y motas ha eliminado tres meandros y aislado sus enclaves naturales (Ollero et al., 2011). El mismo tramo inferior del río Segura, hasta su desembocadura en Guardamar, ha sido objeto en 1981 de un nuevo encauzamiento, esta vez más drástico, con numerosas cortas de meandro y un incremento significativo de la pendiente del lecho, que parecen haber interrumpido el ritmo de acreción sedimentaria dentro del cauce (Conesa García, 1995, 1999). Recientemente en el Ebro se han producido actuaciones también drásticas poco justificables: se multiplican las obras de defensa al mismo tiempo que se invade el terreno de los sotos con cultivos y plantaciones de chopos (Ollero, 1996). Otro ejemplo en este sentido lo constituyen las obras de acondicionamiento y rectificación de los ríos Onyar y Ter, en las proximidades de Girona (Castells et al., 1992), o la construcción de defensas en los márgenes de diversos tramos del río Algar (comarca de Marina Baja) afectados por el paso de la autopista A-7 (C.H.J., 2011).

Frente a este tipo de actuaciones, empiezan a surgir ciertas iniciativas de restauración fluvial encaminadas a devolver a los ríos su espacio y su dinámica natural. Una de ellas es el Plan Nacional de Restauración de Ríos, elaborado en 2006 por el Ministerio de Medio Ambiente y la Confederación Hidrográfica del Ebro, que incluye entre sus objetivos primordiales la conexión hidrológica de meandros que habían quedado aislados por un anterior encauzamiento en el tramo bajo de los ríos Arga (Figura № 8) y Aragón.

Efectos especialmente negativos, a veces profundas incisiones, se observan aguas abajo de tramos totalmente canalizados dentro de los espacios urbanos (Rambla de Belén en Almería, Rambla de la Santa en Totana, la Rambla de las Ovejas en Alicante, etc.). Como resultado de las actuaciones de encauzamiento en ramblas y barrancos de la Marina Baja (Alicante), se desarrollan procesos agudos de encajamiento de la red en algunos cauces, tales como los de cabecera del barranco de la Cala o el tramo final del Derramador. Estos procesos de incisión pueden generar problemas futuros sobre las infraestructuras situadas aguas arriba, al provocar el descalce de cimentaciones por erosión remontante (C.H.J., 2011). 
Figura $\mathrm{N}^{\circ} 8$

Actuaciones en el río Arga (Soto Sardillas, Funes) y en el Bajo Segura (meandro de Las Norias, Beniel).
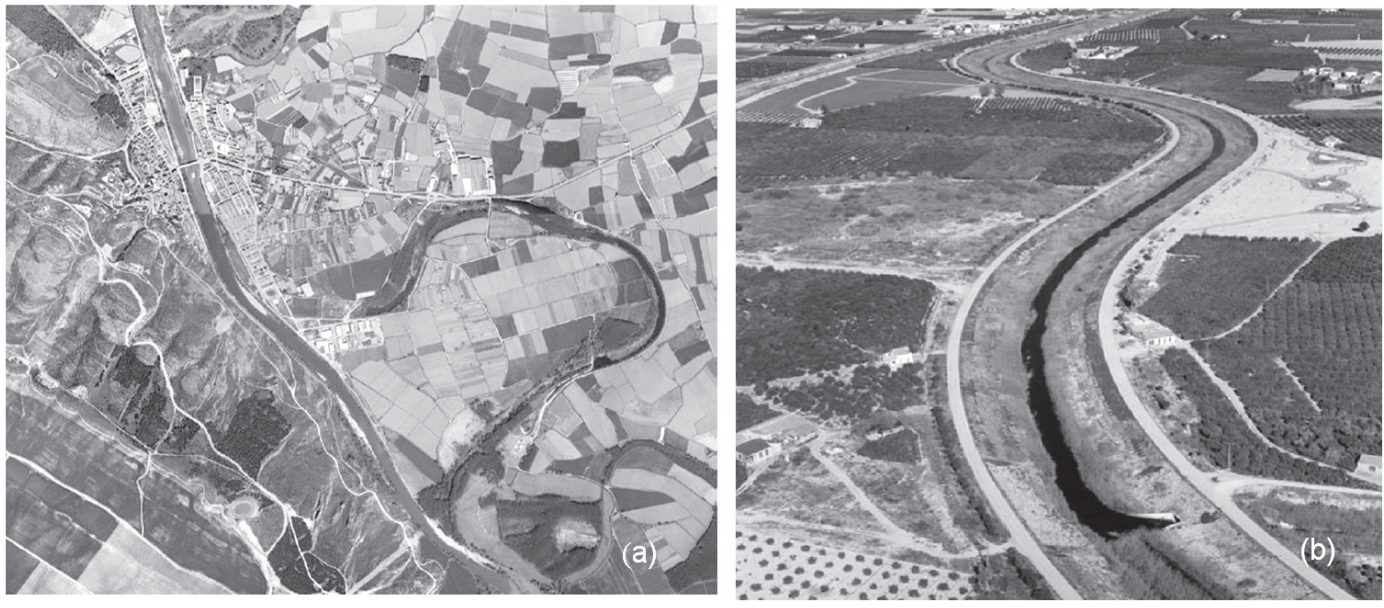

Fuente: Imagen (a) (PNRR, 2006); Fotografía (b) (Archivos C.H.S.)

En el tramo bajo del Barranco del Derramador, a su paso por la ciudad turística de Benidorm, se observa una marcada incisión del cauce sobre su antiguo lecho, con presencia de abundante material grueso (Figura $\mathrm{N}^{\circ}$ 9d). El constreñimiento artificial del barranco, así como la artificialización del perfil longitudinal del cauce excavado bajo la trama urbana de Benidorm contribuyen a explicar este acusado proceso de incisión. Los canales diseñados para este tipo de tramos resuelven la evacuación del caudal líquido, pero técnicamente no son efectivos para el transporte sólido, alterándolo considerablemente (Ollero et al., 2008).

La práctica de las escolleras se ha extendido ampliamente en todo tipo de cauces, imprimiendo un carácter artificial a muchos paisajes fluviales y, lo que es más importante, reduciendo las áreas fuente de sedimento dentro del propio cauce. Además, edificios, vías de comunicación, acequias y otras infraestructuras adosadas a los márgenes tienen con frecuencia el mismo efecto. A esta problemática hay que añadir la originada por los dragados, extracciones, solados o limpiezas de vegetación en el propio cauce menor, hecho que altera de forma significativa los procesos naturales de acreción e incisión. Junto a la acción de los embalses, esta es la causa de los graves problemas de incisión obser- vados en el curso medio del Ebro, afluentes de este (Ollero et al., 2004) y diversas rieras catalanas. Son numerosos los ejemplos de extracciones de áridos y dragados que, al desencadenar procesos de erosión remontante o progresiva han puesto en peligro la estabilidad de puentes, carreteras y azudes (Figura $N^{\circ}$ 9b y 9e). Los casos más llamativos observados en los últimos años corresponden a tramos de ramblas. Estas constituyen el sistema fluvial más dinámico y cambiante en la vertiente mediterránea peninsular. Por tratarse de cauces secos la mayor parte del año y reunir condiciones de fácil acceso y explotación sus lechos de arenas y gravas son objeto de intensas extracciones que conllevan a profundas incisiones durante las avenidas.

Por otra parte, la ocupación urbana de los espacios fluviales, dentro de este ámbito mediterráneo, está teniendo un gran impacto sobre su morfodinámica natural. Cada vez se realizan más actuaciones directas en cauces y riberas ligadas a procesos de urbanización, que terminan provocando graves desequilibrios en la dinámica y morfología de dichos sistemas. Ejemplos de este tipo son muy frecuentes en todo el territorio español, pero alcanzan especial impacto en áreas urbanas con drenaje efímero y avenidas relámpago (flash floods). Tal es el caso de numerosos cauces secos geomorfológicamente activos 
Figura $\mathrm{N}^{\circ} 9$

Rambla de Pastrana (Murcia), incisión provocada por la avenida del 20 de octubre de 2000; (b) río Tordera, 1970-2002 (extracción de áridos). (c) Río Gallego (Zaragoza), incisión en 1970-2000. (d) Incisión del Barranco del Derramador a su paso por Benidorm (Alicante). (e) Rambla de Béjar tras la avenida del 28 de septiembre de 2012, responsable de la destrucción de la autovía A-7 del Mediterráneo a su paso
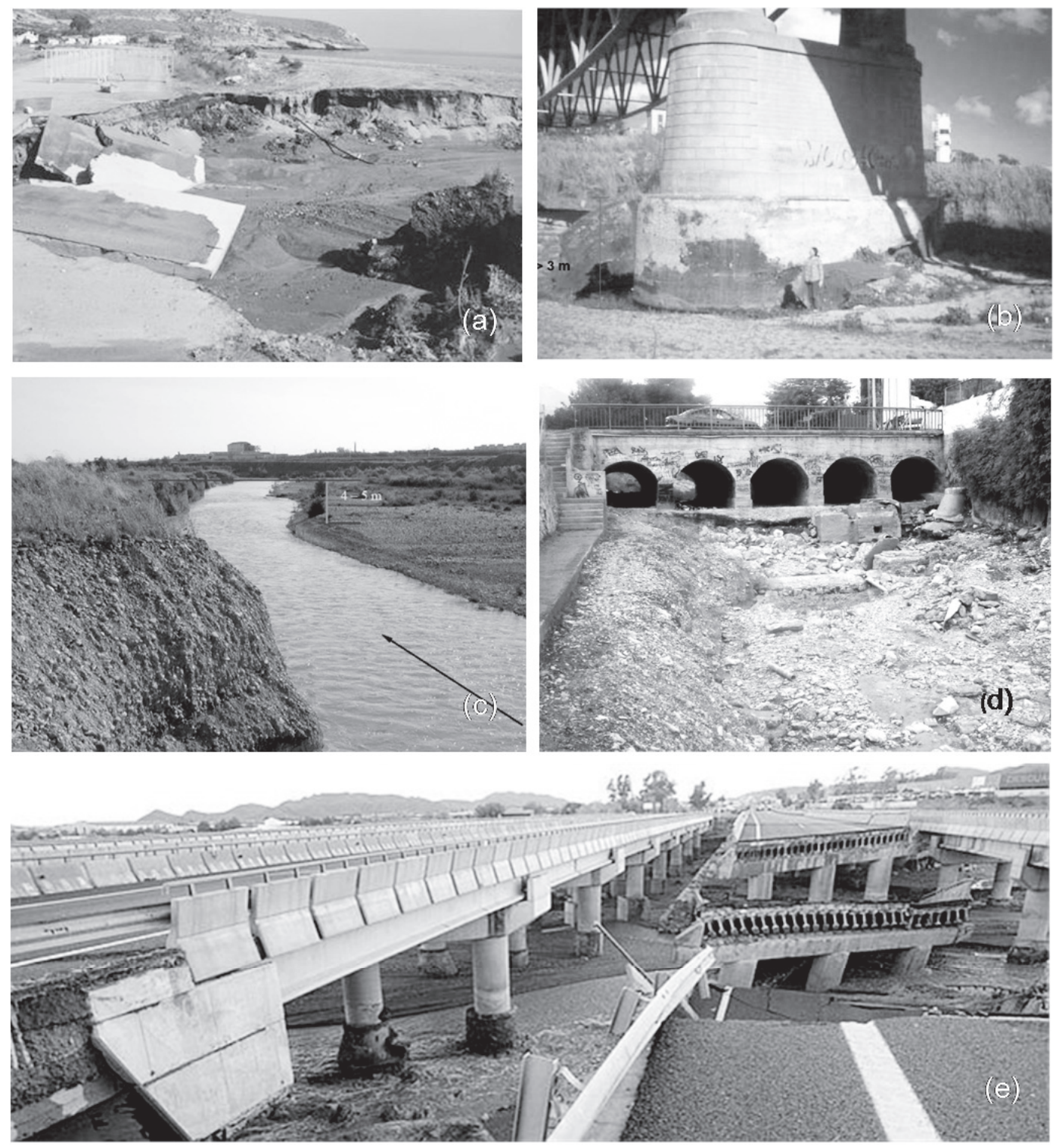

Fuente: Fotografia (a), (b) y (c) ( J.P. Martín Vide); fotografía (d) (C.H.J., 2011); fotografía (e) (Diario La Verdad de Murcia, 2012).

que atraviesan diversos núcleos urbanos en las provincias de Almería, Murcia y Alicante. En la Marina Baja de Alicante, por ejemplo, el desarrollo urbano de Altea hacia el río
Algar ha generado problemas al invadir su espacio inundable e incluso su lecho principal en el tramo próximo a la desembocadura. La intensa urbanización que pavimenta casi 
completamente los conos aluviales al pie de la Serra Gelada y grandes superficies del entorno de I'Alfàs del Pi, en la cuenca del Riu Sec o Rambla de I'Albir constituyen, dentro de esta comarca, otro ejemplo paradigmático (C.H.J., 2011). Como resultado están apareciendo nuevas formas de incisión aguas abajo y de retroceso en la línea de costa.

\section{Conclusiones}

En un proceso de reajuste dinámico del cauce a nuevas condiciones medioambientales, la inestabilidad es transitoria, pero también necesaria para alcanzar dichos estados. Los cambios originados aguas arriba influyen aguas abajo con un retardo temporal causaefecto, especialmente en los tramos medio e inferior de los cursos fluviales. Con frecuencia, estos cursos atraviesan fases transitorias y se hallan sometidos a continuos cambios muchas veces inducidos por la acción del hombre. La mayoría de los ajustes morfodinámicos recientes producidos en los sistemas fluviales mediterráneos de la Península Ibérica tienen como causa principal la modificación del volumen y régimen de aportaciones hídricas en la cuenca o en el propio curso aguas arriba. Desde mediados del siglo $X X$ hasta la actualidad el funcionamiento hidrológico y geomorfológico de muchos de estos sistemas, de régimen permanentes o efímero, se ha visto intensamente afectado por la construcción de embalses, diques, derivaciones, retornos, trasvases, cambios de usos del suelo, incendios, repoblaciones y procesos de urbanización. Son muy numerosos los efectos geomorfológicos que derivan de tales actuaciones (erosión lineal o marginal del cauce, cambios en su sección transversal, acorazamiento del lecho, entre otros). De todos ellos, la incisión del cauce, unida a la erosión transitoria del lecho en sucesos de avenidas o crecidas, constituye el proceso inducido más sintomático y notorio por cuanto afecta directamente a la vegetación ripícola, al nivel freático y a las infraestructuras viarias e hidráulicas que lo atraviesan. Situaciones especialmente graves se observan en zonas de expansión urbana no debidamente planificada, espacios turísticos costeros, o cruces de carretera con corrientes torrenciales, cuando las aguas de avenida incrementan su potencial erosivo, ya de por sí considerable, en respuesta a dichas actuaciones. Desde una perspectiva de gestión es posible identificar la historia de estas alteraciones antrópicas y de sus consecuencias. La cuestión es si la elevada ocupación de las Ilanuras aluviales, cuando no de las zonas de inundación o de los propios cauces, deja suficiente espacio para devolver al río su dinámica natural con la variabilidad que le caracteriza y, todo ello, sin aumentar el riesgo de pérdidas materiales o humanas en condiciones hidrológicas extremas. Recuperar la dinámica natural de ríos y ramblas en la vertiente mediterránea española es hoy día una tarea harto complicada, pero necesaria, en aras de restablecer niveles de equilibrio estable que permitan una adecuada relación del hombre con su entorno. Se impone, por tanto, la conveniencia de redefinir la demanda de recursos hidrológicos en clave de sostenibilidad ambiental, realizar una correcta evaluación hidrogeomorfológica de los tramos fluviales afectados y adoptar políticas de restauración fluvial efectivas acordes con las funciones naturales de los mismos.

\section{Referencias bibliográficas}

ACÍN, V.; DÍAZ BEA, E.; GRANADO, D.; IBISATE, A. y OLLERO, A. Cambios recientes en el cauce y la llanura de inundación del área de confluencia Aragón-Arga (Navarra). Geographicalia, 2011, No 59-60, p. 11-25.

AYUSO, J.; CIRIA, F. y GIRÁLDEZ, J.V. Perspectivas hidrológicas de las zonas áridas. En: Seminario sobre zonas áridas. Almería: Diputación de Almería, 1982, p. 159-172.

BATALLA, R.J.; VERICAT, D. y PALAU, A. Efectos de las presas en la dinámica geomorfológica del tramo bajo del Ebro. Crecidas controladas. Ingeniería del Agua, 2008, Vol. $15, N^{\circ} 4$, p. 243-255.

BURLANDO, P.; MANCINI, M. \& ROSSO, R. Impact of climate change on hydrological modelling and flood risk assessment. In: CASELE, R.; HAVNO, K. \& SAMUELS, P. River basin modeling management and flood mitigation. IV EU Programe on Environment and Climate. Proceedings of the First Expert Meeting. Brussels, 1997, p. 7-26.

CARMONA GONZÁLEZ, P. y OLMOS LLORÉIS, J. Río y ciudad: El caso de Valencia. 
Revista del Colegio de Ingenieros de Caminos, Canales y Puertos de Cataluña, Comunidad Valenciana, Extremadura, 1994, № 28, p. 34-39.

CASTELLS, R.; CATLLAR, B. y RIERA, J. Catàleg de plànols de la Ciutat de Girona des del segle XVII al XX. Atlas de Girona Ciutat. Girona: Ed. COAC, 1992, p. 230-374.

CHIEN, N. Changes in river regime after the construction of upstream reservoirs. Earth Surface Processes Landforms, 1985, № 10, p. 143-159.

CONACHER, A.J. \& SALA, M. Land degradation in Mediterranean environments of the world: Nature and extent cause and solutions. New York: John Wiley \& Sons, 1998, p. 491.

CONESA GARCÍA, C. Torrential Flow Frequency and Morphological Adjustments of Ephemeral Channels in South-East Spain. In: HICKIN, E.J. River Geomorphology. Chichester: John Wiley \& Sons, 1995, p. 169-192.

CONESA GARCÍA, C. Cambio ambiental y equilibrio dinámico de los cauces. Papeles de Geografía, 1999, № 30, p. 31-46.

CONESA GARCIA, C. Les ramblas du Sudest Espagnol: Systèmes hydromorphologiques en milieu méditerranéen sec. Zeitschrift für Geomorphologie, 2005, Vol. 2, No 49, p. 205-224.

CONESA GARCÍA, C.; GARCÍA LORENZO, R. \& LÓPEZ BERMÚDEZ, F. Bed stability variations after check dam construction in torrential channels (South-East Spain). Earth, Processes and Land Forms, 2007, No 32, p. 2165-2184.

CONESA-GARCÍA, C. \& GARCÍA LORENZO, R. Bed scour-sedimentation balance induced by check dams in semiarid catchments with different lithology. In: CONESA GARCÍA, C. \& LENZI, M.A. Check Dams, Morphological Adjustments and Erosion Control in Torrential Streams. New York: Nova Science Publishers, 2010, p. 283-306

CONESA GARCÍA, C.; PÉREZ CUTILLAS, P.; GARCÍA LORENZO, R. Y MARTÍNEZ SALVADOR, A. Cambios históricos recientes de cauces y llanuras aluviales inducidos por la acción del hombre. Nimbus, 2012, № 29-30, p. 159-176.

CONFEDERACIÓN HIDROGRÁFICA DEL JÚCAR (C.H.J.). Plan Director de Defensa contra las avenidas en la comarca de la Marina Baja. Apéndice 3, Estudio Geomorfológico. Valencia: Ministerio de Medio Ambiente y Medio Rural y Marino, CHJ, 2011, p. 24-166.

DE ANTONIO, R.; ALMOROX, J.; SAA, A. y RUEDA, J.P. Erosión y aterramiento de embalses, Agricultura, 1995, Vol. 64, No 751, p. 151-154.

FERNÁNDEZ-GALIANO, E. Pasado, presente y futuro de los bosques de la Península Ibérica, Acta Botánica Malacitana, 1990, No 15, p. 135-143.

FREIXAS BORREL, G. y JIMÉNEZ MUR, P.J. Estudio para la implementación de las técnicas de arrastre hidráulico y corrientes de turbidez en el sistema de embalses Mequinenza-Ribarroja d'Ebre-Flix: viabilidad técnica y percepción social. Máster en Gestión Fluvial Sostenible y Gestión Integrada de Aguas 2010-2012, 2012, №3, p. 83-88.

GARCÍA DE JALÓN, D.; SÁNCHEZ NAVARRO, R. y SERRANO, J. Alteraciones de los regímenes de caudales de los ríos. En: GONZÁLEZ DEL TÁNAGO, M. (coordinadores). Estrategia Nacional de Restauración de Ríos. Madrid: Subdirección General de Gestión Integrada del Dominio Público Hidráulico (Ministerio de Medio Ambiente) y UPM, 2007, p. 41-66.

GARCÍA RUIZ, J.M.; WHITE, S.; MARTÍ, C.; VALERO, B.; ERREA., M.P. y GÓMEZ VILLAR, A. La catástrofe del barranco de Arás (Biescas, Pirineo Aragonés) y su contexto espacio-temporal. Zaragoza: Instituto Pirenaico de Ecología, 1996.

GÓMEZ, R.; HURTADO, I.; SUÁREZ, M.L. y VIDAL ABARCA, M.R. Ramblas in Southeast Spain: threatened and valuable ecosystems. Aquatic Conservation: Marine and Freshwater Ecosystem, 2005, № 15, p. 387-402.

GT8 VII CNMA. Restauración Hidrológico-Forestal: pasado, presente y futuro. En: CNMA. Madrid: VII Congreso Nacional del Medio Ambiente, 2004, p. 45-47. 
JASO, C.; IBARRA, J. y DEL AMO, E. LOS ríos gestionan sus propias crecidas, Pamplona: Fundación Nueva Cultura del Agua en Navarra, 2007. Disponible en Internet: http://www.yesano.com/opinion/FNCA_Navarra_20070513.htm.

JOHNSON, W.C. Dams and riparian forests: Case study from the Upper Missouri River. Rivers, 1992, No 3, p. 229-242.

LIGON, F.K.; DIETRICH, W.E. \& TRUSH, W.J. Downstream ecological effects of dams, a geomorphic perspective. BioScience, 1995, No 45, p. 183-192.

LÓPEZ ALONSO, R.; PONS PUY, P. y BATALLA, R.J. Efectos hidrogeomorfológicos aguas abajo de los embalses. Cimbra, 2004, No357, p. 22-28.

LÓPEZ BERMÚDEZ, F. y GUTIÉRREZ ESCUDERO, D. Estimación de la erosión y aterramientos de embalses en la cuenca hidrográfica del Río Segura. Cuadernos de Investigación Geográfica, 1982, № 8, p. 3-18.

LÓPEZ BERMÚDEZ, F. Evaluación de la erosión hídrica en las áreas receptoras de los embalses de la Cuenca del Segura. Aplicación de la U.S.L.E. En: COMTAG. Estudios sobre Geomorfología del Sur de España, Murcia: Universidad de Murcia - University of Bristol, 1986, p. 93-97.

LÓPEZ BERMÚDEZ, F.; CONESA GARCÍA, C. y ALONSO SARRÍA, F. Ramblas y barrancos mediterráneos: medio natural y respuesta humana. Mediterrâneo, 1998, Nº 12-13, p. 223-242.

MARTÍN VIDE, J.P. Ingeniería de ríos. Barcelona: Edicions UPC, 2006.

MATEU BELLÉS, J.F. Ríos y ramblas mediterráneos. En: GIL OLCINA, A. y MORALES GIL, A. Avenidas fluviales e inundaciones en la cuenca del Mediterráneo. Alicante: Instituto Universitario de Geografía de la Universidad de Alicante, 1989, p. 133-150.

MENANTEAU, L. y VANNEY, J.R. El cauce del Bajo Guadalquivir: morfología, hidrología y evolución histórica. En: El Río: El Bajo Guadalquivir. Sevilla: Junta de Andalucía, 1985, p. 116-136.
MORALES GIL, A. El riego con aguas de avenida en las laderas subáridas. Papeles del Departamento de Geografía de Murcia, 1969, $N^{0} 1$, p. 167-183.

MUÑOZ, J.A. y NAVARRO, I. La rambla de Chirivel. Estudio de un sistema hidráulico tradicional en la comarca de Los Vélez. Revista Velezana, 2000, № 19, p. 91-104.

OlLERO, A. El curso medio del Ebro: geomorfología fluvial, ecogeografía y riesgos. Zaragoza: Consejo de Protección de la Naturaleza de Aragón, 1996.

OLLERO, A. Territorio fluvial. Diagnóstico y propuesta para la gestión ambiental y de riesgos en el Ebro y los cursos bajos de sus afluentes. Bilbao: Bakeaz y Fundación Nueva Cultura del Agua, 2007.

OLLERO, A.; CADIÑANOS, J.A.; DÍAZ BEA, E.; ELOSEGI, U.; GARCÍA MURGA, F.; IBISATE, A.; MEAZA, G.; ORMAETXEA, O. y SÁENZ DE OLAZAGOITIA, A. Análisis y diagnóstico del sistema fluvial y propuestas para la gestión de un tramo regulado en el río Cinca (Huesca). En: CGE. Actas del XVII Congreso de Geógrafos Españoles. Oviedo: CGE, 2001, p. 185-188.

OLLERO, A.; SÁNCHEZ, M.; MARÍN, J.M.; FERNÁNDEZ, D.; BALLARÍN, D.; MORA, D.; MONTORIO, R.; BEGUERÍA, S. y ZÚÑIGA, $M$. Caracterización hidrogeomorfológica del Río Gállego. En: PEÑA, J.L.; LONGARES, L.A. y SÁNCHEZ, M. Geografía Física de Aragón. Aspectos generales y temáticos. Zaragoza: Universidad de Zaragoza e Institución Fernando el Católico, 2004, p. 117-129.

OlLERO OJEDA, A. y ROMEO GARCÍA, R. Alteraciones geomorfológicas de los ríos. En: GONZÁLEZ DEL TÁNAGO, M. Estrategia Nacional de Restauración de Ríos. Madrid: Subdirección General de Gestión Integrada del Dominio Público Hidráulico (Ministerio de Medio Ambiente) y UPM, 2007, p. 187224.

OLLERO, A.; BALLARÍN, D.; DÍAZ BEA, E.; MORA, D.; SÁNCHEZ FABRE, M.; ACÍN, V.; ECHEVERRÍA, M.T.; GRANADO, D.; IBISATE, A.; SÁNCHEZ GIL, L. y SÁNCHEZ GIL, N. IHG: un índice para la valoración 
hidrogeomorfológica de sistemas fluviales. Limnetica, 2008, Vol. 1, № 27, p. 171-188.

OLLERO, A.; IBISATE, A.; GONZÁLEZ DE MATAUCO, V.; NAVERAC, A.; DÍAZ, E.; GRANADO, D. y GARCÍA, J. H. Innovación y libertad fluvial. En: CIGPA. VII Congreso Ibérico sobre Gestión y Planificación del Agua "Ríos Ibéricos +10. Mirando al futuro tras 10 años de DMA". Talavera de la Reina: CIGPA, 2011, p. 4-14.

PALAU, A. Integrated environmental management of current reservoirs and regulated ri-vers. Limnetica, 2006, Vol. 25, № 1-2, p. 287-301.

PLAN NACIONAL DE RESTAURACIÓN DE RÍOS (PNRR). Conexión hidrológica de meandros en los tramos bajos de los ríos Arga y Aragón. Madrid: Ministerio de Medio Ambiente, C.H.E., 2006.

PULIDO BOSCH, A. Las ramblas mediterráneas; condicionantes geomorfológicos e hidrológicos. En: IEA. Las ramblas mediterráneas, Actas de la VI Aula de Ecología. Madrid: Instituto de Estudios Almerienses, 1993, p. 131-140.

ROMERO DÍAZ, M.A.; CABEZAS, F. \& LÓPEZ BERMÚDEZ, F. Erosion and fluvial sedimentation in the River Segura basin (Spain). Catena, 1992, № 19, p. 379-392.

SABATÉ J.; VERICAT D. y BATALLA R. Cambios morfológicos y de vegetación en el tramo bajo del río Ebro durante el siglo XX. XII Reunión Nacional de Geomorfología, Santander, 2011, p. 517-520.

SANZ MONTERO, M.E.; AVENDAÑO SALAS, C. y COBO RAYÁN, R. Influencia del complejo de embalses Mequinenza-Ribarroja-Flix (río Ebro) en la morfología del cauce situado aguas abajo. Revista de la Sociedad Geológica de España, Vol. 1-2, № 14, 2001, p. 3-17.
SCHUMM, S.A. The fluvial system. New York: John Wiley and Sons, 1977.

SEAR, D.A. \& NEWSON, M.D. Environmental change in river channels: a neglected element. Towards geomorphological typologies, standards and monitoring, The Science of the Total Environment, 2003, No 310, p. 17-23.

SEGURA, F. Las ramblas valencianas. Algunos aspectos de hidrología, geomorfología y sedimentología. Valencia: Universidad de Valencia, 1990, p. 196-212.

SIMON, A. \& DARBY, S.E. Effectiveness of Grade-Control Structures in Reducing Erosion along Incised River Channels: The Case of Hotophia Creek, Mississippi. Geomorphology, 2001, Vol. 3-4, № 42, p. 229-254.

TORRES ALFOSEA, F.J. El riesgo de temporales en el litoral de la provincia de Alicante. En: GIL OLCINA, A., OLCINA CANTOS, J. y RICO AMORÓS, A.M. Aguaceros, aguaduchos e inundaciones en áreas urbanas alicantinas. Alicante: Publicaciones de la Universidad de Alicante, 2004, p. 145-198.

URIBELARREA，D.; PÉREZ-GONZÁlEZ, A. \& BENITO, G. Channel changes in the Jarama and Tagus rivers (central Spain) over the past 500 years. Quaternary Science Reviews, 2003, No 22, p. 2.209-2.221.

VERDÚ, J.M. Análisis y modelización de la respuesta hidrológica y fluvial de una extensa cuenca de montaña mediterránea (río Isábena, Pre-Pirineo). Lleida: Departament de Medi Ambient i Ciències del Sòl, Universitat de Lleida, 2003.

VERICAT, D. y BATALLA, R.J. Efectos de las presas en la dinámica fluvial del curso bajo del río Ebro. Revista Cuaternario y Geomorfología, 2004, Vol. 1-2, № 18, p. 37-50. 